\title{
Redução da severidade do mofo cinzento em mudas de Eucalyptus benthamii tratadas com Trichoderma atroviride
}

\author{
José Antonio Sbravatti Junior'; Carolina Gracia Poitevin²; Diogo Robl2; Álvaro Figueredo dos Santos ${ }^{3}$; Ida Chapaval \\ Pimentel $^{2}$; Patrícia do Rocio Dalzoto ${ }^{2}$ Celso Garcia Auer ${ }^{3}$
}

${ }^{1}$ Programa de Pós-graduação em Engenharia Florestal, Universidade Federal do Paraná, CEP Curitiba, PR, Brasil. ${ }^{2}$ Programa de Pós-graduação em Microbiologia Patologia Básica, Universidade Federal do Paraná, Curitiba, PR, Brasil. ${ }^{3}$ Embrapa Florestas, CP 319, 83411-000, Colombo, PR, Brasil. ${ }^{3}$ Bolsista CNPq.

Autor para correspondência. Celso Garcia Auer (celso.auer@embrapa.br).

Data de chegada: 26/01/2016. Aceito para publicação em: 22/08/2016.

$10.1590 / 0100-5405 / 2148$

\section{RESUMO}

Sbravatti Junior, J.A.; Poitevin, C.G.; Robl, D.; Santos, A.F. dos; Pimentel, I.C.; Dalzoto, P.R.; Auer, C.G. Redução da severidade do mofo cinzento em mudas de Eucalyptus benthamii tratadas com Trichoderma atroviride. Summa Phytopathologica, v.42, n.4, p.363-365, 2016.

O mofo cinzento, causado por Botrytis cinerea, é responsável por mortalidade em mudas de Eucalyptus benthamii. O controle biológico é uma alternativa, devido à falta de produtos registrados para eucalipto no Brasil. Este estudo avaliou o fungo endofítico Trichoderma atroviride, isolado de eucalipto, para controle de $B$. cinerea. $O$ ensaio consistiu na aplicação de uma suspensão de esporos de T. atroviride em mudas de E. benthamii, 24, 48 ou 72 horas antes de inocular $B$. cinerea. Como controle positivo utilizou-se iprodione. Mudas inoculadas foram mantidas em casa de vegetação por 21 dias. A severidade foi avaliada com auxílio de escala de sintomas de 0 (sem lesões) a 4 (alta severidade). Trichoderma atroviride reduziu significativamente a severidade da doença, independentemente do tempo de aplicação prévio, de modo similar ao fungicida.

Palavras-chave: Botrytis cinerea, eucalipto, viveiro

ABSTRACT

Sbravatti Junior, J.A.; Poitevin, C.G.; Robl, D.; Santos, A.F. dos; Pimentel, I.C.; Dalzoto, P.R.; Auer, C.G. Reduction in gray mold severity in Eucalyptus benthamii seedlings treated with Trichoderma atroviride. Summa Phytopathologica, v.42, n.4, p.363-365, 2016.

Gray mold, caused by Botrytis cinerea, is responsible for mortality of Eucalyptus benthamii seedlings. Biological control is an alternative due to the lack of products registered for eucalyptus in Brazil. This study evaluated the endophytic fungus Trichoderma atroviride, isolated from eucalypt, for controlling $B$. cinerea. The assay consisted in the application of a spore suspension of $T$. atroviride on E. benthamii seedlings at 24,
48 or $72 \mathrm{~h}$ before $B$. cinerea inoculation. Iprodione was used as positive control. Inoculated seedlings were maintained in a greenhouse for 21 days. Severity was evaluated based on a scale of symptoms from 0 (no lesions) to 4 (high severity). Trichoderma atroviride significantly reduced the disease severity, independent of the time of previous pulverization, similarly to the fungicide.

Keywords: Botrytis cinerea, eucalyptus, nursery.

As baixas temperaturas e geadas da região Sul do Brasil exigem o plantio de espécies tolerantes, como Eucalyptus benthamii Maiden et Cambage, originária do Sul da Austrália. Por sua rusticidade, bom crescimento e forma do fuste existe uma grande demanda por mudas dessa espécie. Entretanto, o mofo cinzento (Botrytis cinerea Pers.: Fr.) é uma doença comum em mudas de $E$. benthamii, causando sua morte e prejuízos em viveiros comerciais (1). O mofo cinzento é controlado por práticas culturais e uso de fungicidas. Segundo Bizi (3), fungicidas são utilizados em viveiros florestais, somente em casos de elevada severidade e pela falta de produtos registrados para a cultura de eucalipto. Estes fatores têm estimulado o uso do controle biológico.

Os relatos de controle biológico de $B$. cinerea com fungos, no Brasil, apontam para Clonostachys rosea (Link : Fr.) Schroers, Samuels, Seifert and Gams em rosa (9) e fúcsia (13), Trichoderma spp. e Lecanicillium sp. em eucalipto (3) e Trichoderma harzianum Rifai e Gliocladium viride Matr. em tomate (5).

No controle biológico de fitopatógenos, os endófitos participam pela competição espacial e por nutrientes, pelo parasitismo direto e/ou inibição decorrente da produção de metabólitos com ação antibiótica (12) e podem ser empregados, sem prejuízos a planta hospedeira. Existem vários exemplos como Acremonium kilense contra Fusarium oxysporum em tomateiro (2) e Colletotrichum sp., contra Gaeummanomyces graminis var. tritici (6)

Sbravatti Junior et al. (11) selecionando fungos endofíticos in vitro obtidos de mudas sadias de $E$. benthamii contra $B$. cinerea, encontraram: Aspergillus sp., Penicillium sp. e Trichoderma sp. Destes, somente o gênero Trichoderma é reconhecido pelo biocontrole de fungos (7). Assim, este estudo avaliou o efeito de Trichoderma sp. na severidade do mofo cinzento em mudas de $E$. benthamii.

Para tal estudo, um isolado de $B$. cinerea foi obtido de mudas seminais doentes e o isolado endofítico Trichoderma sp. foi obtido de mudas sadias de $E$. benthamii, coletadas de viveiro comercial em Guarapuava, PR (11). Os isolados purificados foram multiplicados em meio BDA (batata-dextrose-ágar; $39 \mathrm{~g}$ de extrato comercial, 1000 $\mathrm{mL}$ água ultrapurificada) e encontram-se preservados na Coleção de Fungos Florestais, Embrapa Florestas, em Colombo, PR. O isolado 
endofítico não se mostrou patogênico em mudas de E. benthamii (10).

Os isolados foram submetidos ao sequenciamento das regiões ITS do DNA ribossomal para a identificação ao nível de espécie, pela comparação com sequências depositadas no GenBank. Foi possível identificar o patógeno Botrytis cinerea (= Botryotinia fuckeliana (de Bary) Whetzel) com número de acesso KJ476441. No caso de Trichoderma sp. verificou-se pertencer à espécie Trichoderma atroviride $\mathrm{P}$. Karst, com número de acesso KC311840.

O bioensaio foi feito em casa de vegetação do Laboratório de Patologia Florestal, Embrapa Florestas, em Colombo, PR, em 2013, usando mudas sadias com $30 \mathrm{~cm}$ de altura. As mudas, procedentes do mesmo viveiro, foram produzidas em tubetes plásticos de $55 \mathrm{~cm}^{3} \mathrm{com}$ substrato constituído de vermiculita, turfa, casca de arroz carbonizada, com traços de calcário dolomítico, de gesso agrícola e fertilizante de liberação lenta.

Os conídios de T. atroviride foram produzidos em meio BDA. Para a produção de conídios de $B$. cinerea, optou-se por uma técnica alternativa em frascos com brotações de árvores jovens de $E$. benthamii esterilizadas, relatada por Sbravatti Junior (10). Este método permite a produção de grande quantidade de conídios deste fungo.

$\mathrm{O}$ ensaio foi montado em delineamento fatorial com quatro tratamentos (testemunha, somente patógeno, T. atroviride e iprodione) $\mathrm{x}$ três tempos de aplicação do endofítico antes do patógeno $(24,48$ ou $72 \mathrm{~h}$ ), sendo utilizadas dez mudas por tratamento. Inicialmente, para a testemunha aplicou-se somente água esterilizada. No tratamento somente patógeno, aplicou-se uma suspensão de conídios de $B$. cinerea em água esterilizada com $3,4 \times 10^{6}$ conídios. $\mathrm{mL}^{-1}$. Nos tratamentos com T. atroviride (24, 48 ou $72 \mathrm{~h})$ aplicou-se uma suspensão de conídios em água esterilizada com $2,87 \times 10^{6}$ conídios.mL $\mathrm{mL}^{-1}$. A concentração de esporos das suspensões foi determinada com o auxílio de câmara de Neubauer, em microscópio ótico (400x). Todas as suspensões de conídios aplicadas nas mudas foram preparadas com água esterilizada mais Tween 20 a $0,01 \%$. No controle positivo, aplicou-se uma solução de iprodione de 2,4 mL. $\mathrm{L}^{-1}$ i. a. (1) em água esterilizada.

Após a aplicação dos tratamentos com T. atroviride, as mudas dos tratamentos com endofítico e iprodione foram pulverizadas com suspensões de conídios de $B$. cinerea ajustadas nas concentrações de $5,5 \times 10^{6}$ e $1,0 \times 10^{6}$ conídios. $\mathrm{mL}^{-1}$, respectivamente. Em seguida, as mudas tratadas foram dispostas em caixas plásticas, separadas segundo os tratamentos, em casa de vegetação, sob condição ambiente.

A severidade das lesões foi avaliada após 21 dias, conforme escala proposta por Bizi (3) para quantificar a severidade do mofo cinzento em eucalipto: 0 = sem lesão; 1 = infecção leve (lesões restritas, sem coalescência); 2 = infecção média (lesões coalescentes na folha, sem atingir a haste); 3 = infecção severa (lesões coalescentes na folha, até atingir a haste) e 4 = infecção muito severa (colonização da muda até a ponteira). A análise da variância foi feita pelo programa SANEST e a comparação das médias pelo teste de Duncan com $1 \%$ de probabilidade.

Em todos os tratamentos testados ocorreu mofo cinzento (Tabela 1), inclusive na testemunha com água, mostrando que algumas das mudas se apresentavam assintomáticas. A severidade foi significativamente menor com as aplicações prévias de T. atroviride e de iprodione se comparado com a severidade das mudas inoculadas somente com $B$. cinerea. No geral, o efeito do endófito foi similar ao fungicida. Como não houve efeito significativo do período de aplicação prévia, o endófito pode ser aplicado previamente a qualquer momento antes do patógeno.

Considerando a severidade média dos tratamentos, percebe-se que $T$. atroviride promoveu redução de $83,5 \%$ do mofo cinzento contra $87,8 \%$ com o uso de iprodione. Esta redução se aproxima da

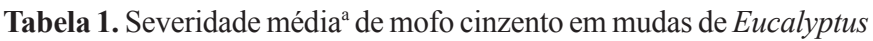
benthamii tratadas preventivamente com Trichoderma atroviride e iprodione, incubadas em casa de vegetação por 21 dias. Colombo, PR. 2013.

\begin{tabular}{ccccc}
\hline Tratamento & \multicolumn{4}{c}{ Aplicação preventiva (h) } \\
\cline { 2 - 5 } & $\mathbf{2 4}$ & $\mathbf{4 8}$ & $\mathbf{7 2}$ & Médias** $^{*}$ \\
\hline Testemunha $^{\mathrm{b}}$ & $1,04 \mathrm{~b}$ & $0,95 \mathrm{~b}$ & $1,12 \mathrm{~b}$ & $1,03 \mathrm{~b}$ \\
Botrytis cinerea $^{\mathrm{c}}$ & $2,04 \mathrm{a}$ & $2,63 \mathrm{a}$ & $2,25 \mathrm{a}$ & $2,30 \mathrm{a}$ \\
Trichoderma atroviride $^{\text {Tredione }}$ & $0,31 \mathrm{~b}$ & $0,36 \mathrm{bc}$ & $0,47 \mathrm{~b}$ & $0,38 \mathrm{c}$ \\
Iprodion & $0,42 \mathrm{~b}$ & $0,07 \mathrm{c}$ & $0,36 \mathrm{~b}$ & $0,28 \mathrm{c}$ \\
\hline Médias & 0,88 & 0,85 & 0,96 & \\
\hline
\end{tabular}

Valores dentro de colunas seguidos por letras iguais não apresentam diferença significativa pelo teste de Duncan $(\mathrm{p}>0,01) . \mathrm{CV}(\%)=33,1 .{ }^{\mathrm{a} e s c a l a}$ de severidade: 0 = ausência de sintomas; 1 = infecção leve; 2 = infecção média; 3

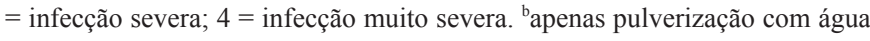
ultrapurificada estéril. ' apenas inoculação de Botrytis cinerea

encontrada por Molina Mercader et al. (8) que estudando Clonostachys spp. e Trichoderma spp. contra B. cinerea em mudas de E. globulus, comprovaram redução média significativa de $85 \%$ da doença.

Este é o primeiro relato de T. atroviride endofítico para o controle de $B$. cinerea em mudas de eucalipto. Etapas futuras de estudo de biocontrole do mofo cinzento deverão contemplar a aplicação de $T$. atroviride em viveiro comercial, analisando concentração da suspensão de conídios e frequência de aplicação.

\section{REFERÊNCIAS}

1. Alfenas, A.C.; Zauza, E.A.V.; Mafia, R.G.; Assis, T.F. Clonagem e doenças de eucalipto. Viçosa, MG: UFV, 2009. 500 p.

2. Azevedo, J.L. Microrganismos endofíticos. In: Azevedo, J.L.; MELO, I.S. Ecologia microbiana. Jaguariúna: Embrapa-CNPMA. p. 117-137, 1998.

3. Bizi, R.M. Alternativa de controle do mofo-cinzento e do oídio em mudas de eucalipto. 2006. 74 f. Dissertação (Mestrado em Engenharia Florestal) - Setor de Ciências Agrárias, Universidade Federal do Paraná, Curitiba.

4. Camargo Filho, M.R. Trichoderma spp. como agentes de biocontrole de Cylindrocladium scoparium e como promotores de crescimento em mudas de eucalipto. 2008. 74 f. Dissertação (Mestrado em Fitopatologia) - Instituto de Ciências Biológicas, Universidade de Brasília, Brasília.

5. Lisboa, B.B.; Bochese, C.C.; Vargas, L.K.; Silveira, J.R.; Radin, B.; Oliveira, A.M.R. de. Eficiência de Trichoderma harzianum e Gliocladium viride na redução da incidência de Botrytis cinerea em tomateiro cultivado sob ambiente protegido. Ciência Rural, Santa Maria, v. 37, n. 5, p. 1255$1260,2007$.

6. Lu, H.; Zou, W.X.; Meng, J.C.; Hu, J.; Tan, R.X. New bioactive metabolites produced by Colletotrichum sp., an endophytic fungus in Artemisia annua. Plant Science, Limerick, v.151, p.67-73, 2000

7. Machado, D.F.M.; Parzianello, F.R.; Silva, A.C.F. da; Antoniolli, Z.I. Trichoderma no Brasil: o fungo e o bioagente. Revista de Ciências Agrárias, Lisboa, v. 35, n. 1. p. 274-288. 2012.

8. Molina Mercader. G.; Flores. S.Z.; Vargas, G.G.; von Stowasser, E.S. Selección de hongos antagonistas para el control biológico de Botrytis cinerea en viveros forestales en Chile. Bosque, Valdivia, v. 27, n. 2, p. 126-134, 2006. doi: 10.4067/S0717-92002006000200007.

9. Morandi, M.A.B.; Maffia, L.A.; Mizubuti, E.S.G.; Alfenas, A.C.; Barbosa, J.G. Supression of Botrytis cinerea sporulation by Clonostachys rosea on rose debris: a valuable component in Botrytis blight management in commercial greenhouses. Biological Control, Orlando, v. 26, n. 3, p. 311-317, 2003

10. Sbravatti Junior, J.A. Seleção in vitro de fungos endofíticos para o controle biológico de Botrytis cinerea em Eucalyptus benthamii. $2013.54 \mathrm{f}$. Dissertação (Mestrado em Engenharia Florestal) - Curso de Pós-graduação 
em Engenharia Florestal, Universidade Federal do Paraná, Curitiba.

11. Sbravatti Junior, J.A.; Auer, C.G.; Pimentel, I.C.; Santos, A.F. dos; Schultz, B. Seleção in vitro de fungos endofíticos para o controle biológico de Botrytis cinerea em Eucalyptus benthamii. Floresta, Curitiba, v. 43, p. 145-152, 2013.

12. Silva, H.S.A.; Bettiol, W.; Terrasan, C.R.F.; Tozzi, J.P.L.; Melo, I.S. de; Nunes, F.V. Microrganismos endofíticos: potencial de uso como agen- tes de biocontrole da ferrugem do cafeeiro. Jaguariúna: Embrapa Meio Ambiente, 2006. 25p. (Embrapa Meio Ambiente. Boletim de Pesquisa e Desenvolvimento, 17)

13. Silvera-Pérez, A.E.; Valdebenito-Sanhueza, R.; Duarte, V.; Santos, H.P.; Felipetto, J. Controle do mofo cinzento com Clonostachys rosea na produção de mudas de fúcsia. Tropical Plant Pathology, Lavras, v. 35, n. 3, p.163-169, 2010 